\title{
PERAN AKTOR NON-NEGARA HUMAN RIGHTS WATCH (HRW) STUDI KASUS ETNIS ROHINGYA DI MYANMAR SEBAGAI BAHAN AJAR BERBASIS PROBLEM BASED LEARNING
}

\author{
Dewi Catur Puji Rahayu \\ Tadris Ilmu Pengetahuan Sosial Fakultas Tarbiyah dan Keguruan IAIN Jember \\ Dewicatur75@gmail.com \\ Depict Pristine Adi \\ Tadris Ilmu Pengetahuan Sosial Fakultas Tarbiyah dan Keguruan IAIN Jember \\ depict.pristine@iain-jember.ac.id \\ Nur Hayati \\ Tadris Ilmu Pengetahuan Sosial Fakultas Tarbiyah dan Keguruan IAIN Jember \\ Nurhytihusna01@gmail.com
}

\begin{abstract}
Abstrak
Tujuan dari penelitian ini yaitu untuk mendeskripsikan peran actor non Negara Human Right Watch dalam kasus Rohingya di Myanmar sebagai salah satu contoh bahan ajar dalam pembelajaran IPS. Dalam artikel ini membahas tentang peran actor non Negara Human right watch dalam kasus kasus rohingya di Myanmar terjadi pada tahun 2016-2018, dalam proses pembelajaran kasus tersebut dapat digunakan sebagai bahan ajar IPS terutama pada materi konflik sosial yang dapat membantu siswa dalam memahami kasus konflik sosial dalam kehidupan bermasyarakat. Metode yang digunakan dalam penelitian ini adalah metode kepustakaan dengan penyajian secara deskriptif dan dianalisis secara kualitatif yang dilakukan dengan cara meneliti bahan-bahan kepustakaan seperti buku, jurnal, dan berita di internet, yang berkaitan dengan obyek yang ditulis. Berdasarkan hasi pembahasan dapat disimpulkan bahwa bentuk deskriminasi yang ditujukan kepada etnis Rohingya tidak dapat dibenarkan apalagi hal tersebut masih dalam lingkup kawasan Asia Tenggara, salah satu upaya penanganan yang dilakukan yaitu dengan bantuan organisasi non Negara yaitu Human Right Watch.
\end{abstract}

Kata kunci: Human Right Watch, Etnis Rohingya, Bahan ajar IPS

\begin{abstract}
Abtract
The purpose of this study is to describe the role of non-State Human Rights Watch actors in the Rohingya case in Myanmar as an example of teaching material in social studies learning. In this article discusses the role of non-State human rights watch actors in Rohingya cases in Myanmar occurred in 2016-2018, in the learning process these cases can be used as social studies teaching materials especially on social conflict material that can help students in understanding social conflict cases in social life. The method used in this study is the method of literature with a descriptive presentation and analyzed qualitatively conducted by examining library materials such as books, journals, and news on the internet, which are related to written objects. Based on the results of the discussion it can be concluded that the form of discrimination aimed at the Rohingya ethnic group cannot be justified especially since it is still within the scope of the Southeast Asian region, one of the handling efforts undertaken is the assistance of non-state organizations namely Human Right Watch.
\end{abstract}

Keyword: Human Right Watch . Etnic Rohingya, Teaching materials IPS

\section{PENDAHULUAN}

Dalam kehidupan bermasyarakat tidak sedikit berkembangnya konflik sosial yang terjadi sehingga menimbulkan keresahan dan hilangnya kedamaian pada masyarakat tersebut, salah satu konflik sosial yang sering terjadi adalah diskriminasi. Menurut UU No. 39 Tahun 1999 tntang hak asasi manusia (2008:27) "Diskriminasi diartikan sebagai setiap oemb atsan atau pengucilan yang dikakukan secara tidak langsung maupun langsung disarkan pada pembedaan 
manusia atas dasar agama, susku, ras, etnik dan kelompok golongan yang berakibat pengurangan, penyimpanan atau penghapusan pengakuan, pelaksanaan, atau penggunaan hak asasi manusia dan kebebasan dasar dalam kehiduapn baik individual maupun kolektif dalam bidang politik, ekonomi, hukum, sosial , budaya, dan aspek kehidupan lainnya." penyebab terjadinya diskrimansi ada beberapa factor yaitu dilatarbelakangi oleh sejarah, perkembangan sosio-kultural, perbedaan keyakinan dan agaman suatu individu atau kelompok dalam sebuah masyarakat. Seperti yang telah terjadi pada masyarakat Myanmar khususnya etnis rohingya dan rakhien, kasus yang telah membuat 140.000 jiwa penduduk tersebut meninggal dunia menjadikan kasus diskriminasi di Rohingya ini telah menarik perhatian dunia internasional." (syarifatul,2017) Konflik etnis yang terjadi di Myanmar ini merupakan konflik antara etnis rohingya yang sebagian besar adalah umat muslim dan etnis Rakhien yang mayoritas penganut Budha. Etnis Rohingya itu sendiri merupakan etnis minoritas muslim yang terdapat pada wilayah Rakhien yang berada dibagian barat pantai Myanmar, keberadaan etnis Rohingya sebagai minoritas etno-religius telah mengalamai mengalami diskirminasi sejak tahun 1982.'Dengan dikeluarkan nya UU kewarganegaraan yang menyatakan menolak atau tidak mengakui minoritas Rohingya sebagai etnis di Myanmar." (syarifatul,2017:20) Pertikaian antar kedua etnis ini sudah terjadi sangat lama dan tercatat di sejarah Myanmar, dan kerap terjadi sepanjang dekade tahun 1990 bahkan sebelumnya.

Myanmar merupakan negara yang merdeka pada 4 Januari 1948 dari Inggris melaui perdamaian antara pemerintah kolonial Inggris dengan kaum nasionalis Burma yang pada saat itu telah dipimpin oleh Thakin Nu. Pada mulanya, Myanmar adalah negara yang dikenal dengan sebutan Burma, pada tahun 1989, nama Burma telah diubah menjadi Myanmar. Sejak berkuasanya rezim junta militer selalu menekan etnis Rohingya dan tidak mengakui Rohingya sebagai masyarakat di Myanmar. (Ayub Tori,2014:258).

Diskirimasi dan pelanggaran HAM yang telah terjadi pada Rohingya telah berlangsung sejak tahun 1980-an membuat 200.000 warga Rohinya melarikan diri ke Bangladesh. Hingga Konflik kembali terjadi pada bulan Juni dan Oktokber denngan melibatkan muslim Rohingya dan etnis Rakhien. Pristiwa tersebut diawaali dengan sebab perampokan dan pelecehan seksual terhadap warga keturunan Budha yang dilakukan oleh seorang muslim, namun tidak sedikit yang mengataakan bahwa tuduhan tersebut hanyalah bentuk strategi kebohongan untuk merencanakan dan melakukan serangan kepada Rohingya. Ratusan minoritas Rohingya telah mengalami ketidakadilan, kerusakan fisik dan mental, selain itu telah terjadi pembatasan terhadap Rohingya baik dalam bidang pekerjaan, dan kebebasan beragama. Kehidupan etnis Rohingya tidak mencerminkan kelayakan hidup , mereka bertempat tinggal di kamp-kamp yang sempit dan sesak, mereka tidak mendapatkan akses bergerak, makan dan air minum bersih sangat susah untuk didapatkan. Kasus deskriminasi yang terjadi Myanmar terhadap etnis Rohingya dapat dikatakan sebagai dikatakan sebagai konflik sosial sebagai sebuah bentuk pembersihan etnis. Bagi pemerintah Myanmar etnis Rohingya dianggap sebagai warga ilegal asal dari Bangladesh yang datang ke Myanmar, sehingga mendapat perlakuan yang diskriminatif oleh pemerintah dan penduduk setempat. Perlakuan tersebut kemudian menjadi akar persoalan munculnya krisis kemanusiaan tersebut.

Dengan penjabaran dan identifikasi dari kasus tersebut, penulis bermaksud untuk menjadikan kasus ini sebagai salah satu contoh bahan ajar IPS khususnya pada materi Konflik sosial sebagai bahan diskusi dengan materi konflik sosial dalam masyarakat. Sehinga penulis merumuskan Judul "Peran Aktor non-negara human rights watch (HRW) dalam kasus etnis Rohingya di Myanmar sebagai bahan ajar IPS dalam Proses Pembelajaran". 
Dari latar belakang masalah yang ada penulis merumuskan rumusan masalah dalam penelitian ini adalah Bagaimanakah peran Human Right Watch (HRW) dalam dalam kasus etnis rohingya di Myanmar serta sebagai bahan ajar yang berbasis PBL $?$.

Dengan tujuan penulisan dalam jurnal ini sebagai berikut: untuk mengetahui peran Human Right Watch (HRW) dalam dalam kasus etnis rohingya di Myanmar, serta sebagai bahan ajar yang berbasis PBL.

\section{HASIL DAN PEMBAHASAN}

Hasil dari kajian kepustakaan yang diperoleh sebagai berikut: Peran Human Righ Watch dalam membantu menangani krisis kemanusia di Myanmar pada kasus Etnis Rohingya , dalam tindakan nya Human Righ Watch melakukan analisis TAN dalam upaya membantu korban Etnis Rohinya, Analisis TAN tersebut Meliputi Information Politics, symbolic Politics, leverage Politics, Accountability Politics.

Penerapan bahan ajar berbasis Problem Based Leraning pada pembelajaran IPS dengan menjadikan kasus Rohingya sebagaisalah satu contoh konflik yang terjadi. Problem Based Leraning adalah pembelajaran yang tidak membosankan dan menjadikan peserta didik tidak merasa terasingkan didalama pembelajaran. Hal ini dikarenakan peserta didik sibuk dengan pembentukan konsep secara mandiri.(Depict Pristine Adi, 2017:143) karakteristik Probem Based Learning sebagai berikut: (1) Belajar dimulai dari masalah; (2) Memastika bahwa masalah yang diberikan berhubungan dengan dunia nyata; (3) Mengorganisasikan pelajaran diseputar masalah, bukan diseputar disiplin ilmu; (4) Menggunkan kelompok kecil. (Esti Zaduqisti,2010:186).

Peran Human Right Watch
(HRW) dalam dalam kasus etnis rohingya di Myanmar. Sejarah atau kronologi dari kasus Rohingya di Myanmar, berawal dari adanya kecemburuan sosial terhadap etnis Rohingya dengan jumlah yang terus mengalami peningkatan hal tersebut kemudian menimbulkan kecurigaan serta kecemburuan pada etnis Rakhien. Menurut Trijoko dalam Jurnal Transnasional
(2013:846) "etnis Budha di Rakhien keberadaan Rohingya dianggap telah mengurani hak atas tanah, lahan dan ekonomi mereka. Khususnya pada wilayah Arakan yang telah menjadi pusat kehidupan etnis Rakhien.” Etnis Rohingya merupakan kelompok etnis yang berasal dari Bangladesh, namun telah bermukim di negara bagian Rakhaing di Myanmar sejak abad ke-7 Masehi.(Dewa Gede,2013:66) Hingga pada tahun 2012 konflik kedua etnis tersebut kembali terjadi, penyebab utama yaitu munculnya isu pelecehan seksual yang dialami oleh seorang wanita Budha bernama Ma Thida Htwe yang telah dilakukan oleh etnis Rohingya. Pasca kejadian tersebut munculah aksi saling serang. Akibatnya diantara kedua etnis tersebut berujung pada pembunuhan dan aksi saling menyerang, bah kan muncul eksodus atau bermigrasinya etnis Rohingya ke wilayah Negara tetangga Myanmar, dengan demikian konflik tersebut telah mengalami diskriminasi, dan mengalamin kerugian serta kerusakan pada rumahrumah, sekolah rumah sakit dan masjid, mereka juga tidak mendapatkan hak pendidikan dan berpenghidupan yang layak serta banyaknya korban yang berjatuhan.

Maka berdasarkan beberapa pemahaman tersebut, peran actor hubungan Internasional khusunya Aktor INGO (Internationla Non-Government Organization) Human Right Watch (HRW) hadir di Myanmar guna membantu etnis Rohingya. Sebagai organisasi Intenasional non pemerintah , HRW pertama kali muncul dengan nama Helsinki Watch yang bertujuan untuk memantau Uni Soviet terkait dengan kepatuhannya terhadap perjanjian Helsinki perjanjian tersebut berkaitan dengan ketentuan hak asasi manusia. (syarifatul,2017:20) Pada tahun 1978 Helsinki Watch dibangun untuk memantau kepatuhan negara-negara blok Soviet dengan ketentuan HAM dari perjanjian Helsinki. Setelah tahun-tahun berikutnya Human Right Watch mengalami perkembangan, kemudian disusul dengan berdirinya Americas Watch yang berfungsi memantau pelanggaran oleh kedua belah pihak dalam perang yang terjadi di Amerika Tengah. Perjalanan karir HRW berawal 
pada tahun 1978 lalu berkembang hingga pada tahun 1998 dengan konsentrasi pada penegakan hak asasi manusia. Pada tahun 1980-an, Asia Watch (1985), Afrika Watch (1988), dan setelah itu kemudian Middle East Watch resmi membentuk The Watch Commotes yang digunakan untuk membentuk Human Rights Wacth. Pada tahun 1988. Setelah semua komite dipersatukan, kemudian The Watch Committees resmi mengadopsi sebua nama Human Right Watch, Dalam tugasnya HRW memiliki tujuan yaitu untuk melindungi hak asasi manusia didunia, mendukung korban atau aktifis yang berupaya untuk berusaha mencegah adanaya diskriminasi ataupun pelanggaran HAM. Keberadaan HRW di Myanmar dikatakan sudah cukup lama berioperasi sejak tahun 1980-an Setelah Myanmar merdeka dari Inggris, negara tersebut telah banyak mengalami berbagai tantangan dalam pemerintahan. Puncaknya adalah konflik etnis tahun 2012 hingga menyebabkan banyaknya korban jiwa dari etnis Rohingya dan penderitaan hingga saat ini. Hal tersebutlah yang kemudian mengundang respon dari masyarakat internasional yang memiliki kekhawatiran akan meluasnya dampak krisis kemanusiaan dari tahun-tahun sebelumnya. Respon tersebut membuat adanya beberapa peran dari organisasi-organisasi yang bergerak dalam bidang kemanusiaan atau hak asasi manusia untuk tidak tinggal diam salah satunya adalah Human Right Watch.

Dalam menjelaskan bagaimana peran HRW pada kasus Rohingya di Myanmar , HRW itu sendiri merupakan organisasi yang termasuk dalam Kategori Transnasional Advocaci Network. Menurut Syarifataul dalam Jurnalnya (2013: ) dalam melakukan perannya HRW melakukan TAN. Analisi TAN meliputi: Information Politics, symbolic Politics, leverage Politics, Accountability Politics.

Information Politics merupakan pengumpulan informasi data dan identifikasi isu yang dilakukan oleh HRW yang digunakan untuk mendukung perjuangan sebuah isu atau konfi. (Syarifatul,2017:22) dalam hal ini HRW telah melakukan penyelidikan yang sistematis dan regular terhadap pelanggaran HAM. Yang dilakukan dengan cara menyelidiki pelanggaran, mengekspos fakta, dan menekan aktor-aktor yang memiliki kekuatan untuk menghormati hakhak serta memberikan keadilan.

HRW juga telah memberikan tekanan kepada Myanmar dengan menyatakan bahwa otoritas Myanmar harus segera melakuakn investigasi PBB sebagai langkah perwujudan keadilan untuk para korban, HRW juga melakukan penekanan kepada pemerintah Myanmar dan militer untuk segera memenuhi jaminan kepada wilayah yang terkena dampak. Dan juga harus segera memungkinkan akses kemanusiaan kepada etnis minoritas yang tengah mengalami kehidupan yang tidak layak, denan melalui data dan fakta yang telah disajikan oleh HRW dalam website sekaligus beberapa akun sosmed, informasi dapat tersebar ke semua sosial media dengan harapan akan banyaknya orang yang mendukung penanganan kasus Rohingya.

Symbolic Politic merupakan salah satu strategi HRW dengan menggunakan symbol-simbol, (Syarifatul,2017:23) aksi dan cerita yang dapat menarik perhatian dan memberikan penjelasan untuk meyakinkan masyarakat agar membantu dan memberikan dukungannya kepada suatu etnis atau kelompok yang mengaalami diskriminasi dan pelanggaran HAM seperti Etnis Rohingya di Myanmar. HRW menggunakan prinsip-prinsip secara universal dengan HAM sebagai dasar argumennya, melalui beberapa gambar karikatur, HRW menyampai kan Symbolic Politics sebagai suatu symbol yang digunakan untuk menggambarkan kondisi Myanmar.

Leverage politics Keberadaan HRW di Myanmar dalam memperjuangkan hak asasi manusia dilakukan dengan independen. Pasalnya tidak ada kerjasama yang dilakukan oleh HRW dengan aktor lain yang dirasa lebih kuat. (Syarifatul,2017:23) Dalam hal ini HRW hanya melakukan berbagai bentuk penekanan dengan cara mendesak beberapa pihak Myanmar yang telah dianggapnya dapat berpengaruh dalam penyelesaian masalah kemanusiaan yang 
terjadi di Myanmar, sehingga dalam strategi TAN pada tahap leverage politics hanya dijelaskan bagaimana tindakan-tindakan yang dilakukan oleh HRW untuk menekan pemerintah Myanmar. Dalam tahapan leverage politics $\mathrm{HRW}$ membuat surat yang ditujukan kepada United Nation High Commissioner for Human Rights (UNHCHR) yang berkaitan dengan diskriminasi dan pelanggaran HAM yang dilakukan oleh etnis Rakhin kepada Rohingya. HRW dan organisasi lain juga telah menulis surat guna mendesak delegasi untuk mendukung panggilan oleh Komisaris Tinggi PBB dalam bidang HAM dan memperbarui mandat Pelapor Khusus dalam hal pembentukan oleh Dewan HAM PBB. Maksud ditulisnya surat tersebut adalah dengan tujuan mendesak Dewan HAM agar segera membentuk penyelidikan internasional independen atas berbagai dugaan pelanggaran yang dilakukan di bagian Rakhine.

Accountability Politics, adalah sebuah jaringan yang digunakan untuk meyakinkan pemerintah dan actor lain agar merubah posisi mereka dalam satu isu, ketika actor atau pemerintah telah mengubah perilaku mereka dalam satu isu maka jaringan mengubah posisinya untuk mengamati dan mengkontrol jenjang diantara janji dan praktiknya.(Syarifatul,2017:23).

Taktik seperti ini perlu digunakan agar tidak terjadi penyimpangan dari komitmen aktor yang ditargetkan. Namun dalam kasus perjuangan HRW, politik akuntabilitas ini belum dapat diterapkan dikarena pemerintah Myanmar ternyata belum menyatakan komitmennya untuk mendukung apa yang sedang diperjuangkan oleh HRW. Karena telah diketahui bahwa Myanmar belum memastikan atas hak warga etnis Rohingya , padalah jika dilihat secara keanggotaan dalam perjanjian dan organisasasi Internasional Myanmar terkait konvensi tentang penghapusan terhadap segala bentuk Diskriminasi terhadap perempuan dan konvensi tentang pencegahan dan penghukuman terhadap kejahatan genosida.

Namun sepertinya perjanjian tersebut belum ditetapkan oleh Myanmar, akhirnya tekanan dan kemarahan public tumbuh dalam menanggapi laporan-laporan yang telah terdokumentasikan kejahatankejahatan dan kekejaman yang dilakukan oleh aparat keamanan Myanmar terhadap Etnis Rohingya.

Kasus Etnis Rohingya di Myanmar Sebagai Bahan Ajar berbasis Problem Bases Learning. Dalam proses belajar mengajar dikelas, keterlibatan pendidik dalam mengajar mengharuskan peserta didik dapat memahami seluruh materi yang diberikan saat KBM berlangsung, untuk memudahkan pendidik memberi pemahaman kepada peserta didik, pendidik perlu menggunakan bahan ajar. salah satu contoh bahan ajar yaitu handout, handout adalah bahan ajar yang berisi tentang materi. Untuk melatih kemampuan siswa dalam berpikir, handout berbasis PBL dapat diteraokan oleh pendidik, seperti pada materi Konflik sosial. Problem Based Learning merupakan pembelajaran yang tidak membosankan dan menjadikan peserta didik tidak merasa terasingkan didalama pembelajaran. Hal ini dikarenakan peserta didik sibuk dengan pembentukan konsep secara mandiri.(Depict Pristine Adi:2017,143) dengan demikian peserta didik akan mampu memikiki kemampuan berpikir kritis dalam memecahkan sebuah persoalan. Dengan karakteristik Problem Based Learning menurut peneliti kasus Etnis Rohingya dapat dijadikan sebuah contoh kasus yang konkrit untuk menjadi dasar diskusi peserta didi mengenai materi IPS tentang Konflik sosial sehingga mereka mampu membangun konsep dengan sendiri bagaiman dan seperti apa sebuah konflik dalam suatu masyarakat. Adapun karakteritik PBL yaitu: (1) Belajar dimulai dari masalah; (2) Memastika bahwa masalah yang diberikan berhubungan dengan dunia nyata; (3) Mengorganisasikan pelajaran diseputar masalah, bukan diseputar disiplin ilmu, dan (4) Menggunkan kelompok kecil. (Esti Zaduqisti,2010:186).

Sebab lain pemilihan kasus Etnis Rohingay sebagai bahan ajar berbasis PBL dikarenakn kasus tersebut dipilih karena dirasa mudah untuk disingkron kan dengan materi Konflik sosial, jika dilihat dari sejarah konflik tersebut maka memudahkan 
peserta didik untuk mengidentifikasi materi konflik sosial jika di kaitkan dengan kasus Etnis Rohingya di Myanmar sebagai salah satu dari contoh konflik sosial yang terjadi di kehidupan masyarakat.

\section{SIMPULAN}

Berdasarkan paparan mengenai kronologi kasus Etnis Rohingya dan Etnis Rakhien di Myanmar, serta penjelasan mengenai peran organisasi Human Right Watch dalam kasus tersebut dapat disimpulkan bahwa kasus yang terjadi di Negara Myanmar sangat tidak dibenarkan , sebagai organisasi non Negara HRW yang bergerak pada bidang advocation kemanusiaa telah mengupayakan dengan berbagai cara untuk membantu perlindungan korban diskriminasi dan pelanggaran di Myanmar, melalu studi kepustakan yang telah dilakukan oleh peneliti, peneliti menjelaskan beberapa cara

\section{DAFTAR PUSTAKA}

Ula, Syarifatul.2017." Peran Aktoe non Negara dalam Hubungan Internasional Studi Kasus Human Right Watch di Myanmar." Jurnal Of Internasional Relations. Departemen Hubungan Internasional, Fakultas Ilmu Sosial dan Ilmu Politik Universitas Diponegoro: 19-28.

Kurniawan, Nalom.2017.'Kasus Rohingya dan Tanggung Jawab Negara dalam Penegakan HAM."Jurnal Konstitusi.Pusat Penelitian dan Pengkajian Perkara Jakarta: 881-903.

Triono.2014."Peran Asean dalam Penyelesaian Konflik

Rohingya."Jurnal TAPIS.Fakultas Ushuludin UIN Raden Intan Lampung: 2-10.

Alunnaza, Hardi.2015."Pran NGO dalam Kasus Etnis Rohingya di Myanmar." Jurnal Transnasional.Hubungan Internasional Universitas Muhammaddiyah Yogjakarta: 3-16.

Waluyo, Trijoko.2013.'Konflik tak Seimbang Antara Etnis Rohingya dan Rakhien di Myanmar."Jurnal Transnasional.Hubungan Internasional FISIP Universitas Riau:838-851. penanganan yang telah dilakukan HRW , yaitu sebagai berikut : 1) HRW menggunakan strategi Information Politics, melalui strategi ini HRW menelusuri kebenaran menggunakan informasi dan identifikasi isu, yang kemudia hasil dari identifakasi tersebut didistribusikan kepada khalayak umum dengan bantuan media sosial untuk mendapat perhatian dan dukungan dari organisai lain , melalui Advokasi HAM nya HRW berhasil meencuri perhatian dunia Internasional, baik actor non pemerintah maupun actor Negara , sehingga actor-aktor tersebut menjadi aware terhadap kasus ini. 2) strategi lain yaitu symbolic politics HRW membuat poster karikatur bergambar dan menggunggah nya ke sosial media, sehingga media sosial dan teknologi yang mendukung ini mampu menyampaikan kasus ini kepada masyarakat Internasional.

Mapata.2017.Penunjang Mata Pelajaran Ilmu Pengetahuan Sosial.Sleman:CV Budi Utama.

Untoro,Yuga,dkk.2016.”Peran ASEAN dalam Penanganan Pengungsian Pencari Suaka yang Ada di Indonesia (studi kasus:pengungsi Rohingya di Aceh)."Low Jurnal." Fakultas hukum Universitas Dipenogoro:1-15.

Adi,Depict Pristine,.2017.'Keefektifan Pendekatan Saintifik Model Problem Based Learning, Problem Solving, dan Inquiry dalam Pembelajaran IPS.”Jurnal Harmony Sosial. "Universitas Negeri Yogjakarta:142-152.

Sudika, Dew Gede.2013."Kasus Pelanggaran HAM Etnis Rohingya: Dalam Prespektif ASEAN."Media Komunikasi FIS. "Fakultas ILmu Sosial Universitas Pendidikan Ghanesa:60-69.

Zaduqisti,Esti.2010."Problm Based Learning(konsep Ide Pembelajaran untu Peningkatan Prestasi Belajar dan Motivasi Berprestasi)."Jurnal Tarbiyah STAIN Pekalongan." Sekolah Tinggi Agama Islam Pekalongan:182-190. 